DIE ROMANTIK IN DER MUSIK 


\section{ALFRED EINSTEIN}

\section{DIE ROMANTIK IN DER MUSIK}

Mit einem Nachwort von

Arnold Feil

VERLAG J.B. METZLER STUTTGART · WEIMAR 
Die Deutsche Bibliothek - CIP-Einheitsaufnahme

Einstein, Alfred:

Die Romantik in der Musik / Alfred Einstein. Mit einem

Nachw. von Arnold Feil. - Stuttgart : Metzler, 1992

ISBN 978-3-476-00848-0

ISBN 978-3-476-00848-0

ISBN 978-3-476-03422-9 (eBook)

DOI 10.1007/978-3-476-03422-9

Dieses Werk einschließlich aller seiner Teile ist urheberrechtlich geschützt. Jede Verwertung außerhalb der engen Grenzen des Urheberrechtsgesetzes ist ohne Zustimmung des Verlages unzulässig und strafbar. Das gilt insbesondere für Vervielfälti. gungen, Übersetzungen, Mikroverfilmungen und die Einspeicherung und Verarbeitung in elektronischen Systemen.

(C) 1992 Springer-Verlag GmbH Deutschland

Ursprünglich erschienen bei J. B. Metzlersche Verlagsbuchhandlung und Carl Ernst Poeschel Verlag GmbH in Stuttgart 1992 


\title{
INHALTSVERZEICHNIS
}

\author{
Vorwort VIII
}

\section{Erster Teil: Charakter}

\author{
1. Kapitel \\ Gegensätze 3
}

Gemeinsamkeiten 7

2. Kapitel

Der Einzelne und die Gesellschaft 11

Beethoven $14 \cdot$ Der romantische Musiker 16 - Nationalismus 17

3. Kapitel

Musik als Zentrum der Kunst 19

Vorherrschaft der Instrumentalmusik 21 - Vielseitigkeit des Musikers 23

4. Kapitel

Musik als Magik 31

Verbindung von Wort und Ton 33

5. Kapitel

Die Widersprüche 37

Die Vereinsamung des Künstlers 38 . Versuch der Überbrückung 39 .

Verhältnis zur Kunst der Vergangenheit 43 - Virtuosität 48

6. Kapitel

Universal- und Nationalmusik 51

7. Kapitel

Die Formen und der Gehalt 61

Lockerung der Form 62 . Die Miniatur 65 


\section{Zweiter Teil: Geschichte}

\section{Kapitel}

Die Entstehung der musikalischen Romantik 71

Beziehung zu Bach 71 . Beziehung zu den »Drei Klassikern« 74 .

Das Suchen nach »Inhalt« bei Beethoven 77

\section{Kapitel}

Der romantische Klassiker: Schubert 81

Der Instrumentalkomponist $83 \cdot$ Schuberts Lied 88

10. Kapitel

Die romantische Oper 95

Romantisierung der Stoffe 97 . Die frühromantische Oper: Weber 99 .

Webers Nachfolger 106 • „Große Oper« 109

11. Kapitel

Sinfonik und Kammermusik 113

Mendelssohn, Schumann, Berlioz, Liszt $113 \cdot$ Brahms, Bruckner 135

12. Kapitel

Chormusik 141

Kirchenmusik 141

13. Kapitel

Oratorium 153

14. Kapitel

Lied 163

Italien 163 - Frankreich 164 - Deutschland: Schumann, Loewe, Franz, Brahms,

Wagner, Liszt, Hugo Wolf. - Mussorgsky 165

15. Kapitel

Universalismus im Nationalen/I 177

Das Klavier: Mendelssohn, Schumann, Liszt, Chopin, Heller, Alkan, Brahms 178

16. Kapitel

Universalismus im Nationalen/II 201

Die neuromantische Oper 201 . Richard Wagner 201 . Zeitgenossen 225 .

Italien: Rossini, Bellini, Donizetti 231 • Giuseppe Verdi 237 .

Opéra bouffe: Offenbach 252

17. Kapitel

Nationalismus 259

Nationale Scheidung im 18. Jahrhundert 261 . Böhmen 261 . Rußland 267 .

Skandinavien 280 Holland 284. Belgien 285 - Ungarn 288 .

Polen 289 S Spanien und Portugal 289 . Nordamerika 292 
INHALTSVERZEICHNIS

Dritter Teil: Musikästhetik und Musikwissenschaft

18. Kapitel

Ästhetik 297

Wissenschaft 310

19. Kapitel

Schluß 315

Nachwort 321

Namenverzeichnis 325 


\section{VORWORT}

Dies Buch ist im Frübjabr 1947 als Teilband einer umfassenden Geschicbte der Musik, geschrieben von verschiedenen Verfassern, in englischer Sprache erschienen. Es unterscheidet sich von den anderen Bänden dieser Reibe darin, daß es auf Notenbeispiele verzichtet und verzichten darf, da das Opernbaus, der Konzertsaal und seit einigen Jabrzehnten der Rundfunk gerade für die in ibm geschilderte Zeit jeden Tag die reichliche Illustration liefern. Es verzichtet ferner auf technische Erörterungen, wie etwa der Entwicklung der romantischen Harmonik, die obne solche Notenbeispiele lebendig nicht darzustellen gewesen wäre. Es ist sich endlich bewußt, daß seine Abgrenzung - die Zeit zwischen dem Tode Beethovens und dem Tode Wagners - nicht obne Willkür ist. Aber feste Abgrenzungen in der Geschichte der Kunst sind immer mehr oder minder willkürlich, und der Rabmen war eben gegeben.

Die Anlage des Buches - ein freundlicher Beurteiler hat sie mit der Form eines Sonatensatzes verglichen, Exposition, Durchführung, Reprise und Coda - bat es mit sich gebracht, daß einige Wiederholungen oder thematische Varianten nicht zu vermeiden waren. Der Leser möge sie gutwillig in Kauf nehmen.

Northampton, Mass.

1. Dezember 1948

Alfred Einstein 